\title{
TRADITIONAL USES OF THE WILD PLANTS, BY THE TRIBAL COMMUNITIES OF JAWHAR, PALGHAR, MAHARASHTRA, INDIA
}

\author{
YATISH LELE ${ }^{1}$, BHARGAVI THORVE ${ }^{2}$, SWATI TOMAR $^{3}$ \&ANJALI PARASNIS $^{4}$ \\ ${ }^{1}$ Forestry and Biodiversity Division, The Energy and Resources Institute, Delhi, India \\ ${ }^{2,3,4}$ Food and Nutrition Security Division, The Energy and Resources Institute, Maharashtra, India
}

\begin{abstract}
The tribal communities have been largely dependent on the wild plants for various purposes such as food, medicine, timber and so on. Several studies have documented this traditional knowledge about wild plants, but mostly related to its dietary and medicinal aspect. The other uses of these wild plants are somewhat ignored and have not been documented so far. This made it necessary, to document the traditional knowledge of the wild plants, used for purposes other than food and medicine. The study was conducted in the tribal areas of Jawhar block, Palghar district, Maharashtra. Around 14 species of plants belonging to 13 families were recognized, for its unique practices of usage. It was found that, the seeds of some plant species are used as a product for barter, fruits as fish toxins, and tender leaves and stems as an external cure, for various ailments. Some plant parts are observed to be used, only for external application, without any processing, to cure diseases and infections. Thus, more of such knowledge should be documented and scientifically validated, as it could help us provide solutions for the future.

KEYWORDS: Wild Plants, Barter System, Tribal Communities, Maharashtra, Traditional Knowledge \& Interesting Uses
\end{abstract}

Received: Sep 17, 2017; Accepted: Oct 03, 2017; Published: Oct 16, 2017; Paper Id.: IJBRDEC20174

\section{INTRODUCTION}

The tribal communities, over several years, have developed a specialized set of practices, using wild forest resources to fulfill their daily needs. This traditional knowledge is a result of the trial and error method, followed over the generations (WIPO, undated).The tribes have shown dependence, mainly on the wild plant species for purposes such as food, medicine, shelter, and so on (Reddy, 2012; Bhogaonkar et. al, 2010). These wild plants have not only proven to be the source of food for daily consumption, but also as a key resource, during extreme situations, such as famines as well (Chothe et. al, 2014; Nene, 2004). Apart from the dietary aspect, the village doctors, locally called as Vaidu, who are aware of the medical properties of the wild edibles, have been successful in providing remedies for several ailments, at the village level (D'souza, 1999; Palekar, 1993). Thus, the wild plants have played a significant role, in the livelihood of the tribal communities, as they mainly prove to be of dietary and medicinal importance. Realizing this significance, several ethno botanical studies have been undertaken, to tap the specific neutraceutical and pharmaceutical potential (Dhore et. al, 2012; Yesodharan and Sujana, 2007; Oak et. al, 2015; Deshmukh and Waghmode, 2011). However, other than their neutraceutical and pharmaceutical potential, very few studies have been found to document other interesting information, on traditional usage.

This information has been sidelined, due to lack of scientific knowledge and documentation (Garud et. al, 
2010; Patil et. al, 2014; Pranjale and Dubey, 2015). Hence, there is a huge gap in understanding the importance and significance of this secondary information, and the applications of the same. Thus, the need to document the perception of the communities becomes necessary, as it would help in improving the understanding of this wild plant species. Moreover, lack of documentation of such interesting observations, may result in the extinction of this traditional knowledge.

The present study, conducted in the Jawhar block, Palghar, Maharashtra, highlights few such observations related to plants, which were identified for its unique and different applications. No similar studies have been documented of the wild plant species, found in Palghar district.

\section{STUDY AREA}

Jawhar taluka lies in Western Ghats, located at $19.92^{\circ} \mathrm{N} ; 73.23^{\circ} \mathrm{E}$ and is bordered by Mokhada Block towards east, Vikramgad Block towards west, Wada Block towards south and Trimbak Block towards North. It is approx. 473 meters, above sea level. Being part of the Northern Western Ghats, the area is rich in biodiversity with a moist deciduous type of the forest ecosystem. The region is inhabited by different tribes like Thakur, Mahadev, Koli, Varli, Katkaris and Kokana, which depend on different wild plants species, for several purposes (Thamizoli and Bapisupati, 2015).

\section{MATERIAL AND METHOD}

A review of literature was undertaken to identify the possible literature present on similar lines. The perceptions were recorded from February 2015- January 2016 through Focused Group discussions (FGD's) in 20 villages of the Jawhar block, which consisted of diverse stakeholders, such as local vaidus (Doctors), men, elderly people as well as women. This approach helped to document the views of all the groups of the community, about the plant species. The observations which presented the unique applications of wild plants in addition to wild edible plants of dietary and medicinal significances were recorded, during this study. The wild plant species were further identified, with the help of Flora of Maharashtra (Almeida, 2003).

\section{RESULTS AND DISCUSSIONS}

In the present study, 14 species of plants belonging to 13 families were identified, based on the unique method of usage, by the tribal communities of Jawhar.

It was observed that, the tribal communities use seeds of 3 plant species, such as Breidelia retusa (Asand/ Spinous Kino), Argemone mexicana (Kardai/ Mexican Prickly Poppy) and Hibiscus cannabinus (Ambadi/ Deccan Hemp), for barter with the vendors in the local market, to purchase potatoes and onions. These seeds are an important source of edible oil which is of significance to the vendors for further sale. This indicated that, the tool of barter system was still being used by the tribal communities, as a part of their economy. Such unique practices, which are still prevalent in the tribal villages need to be studied, in order to obtain the in depth knowledge of their traditional socioeconomic tools. Furthermore, it was observed that, the tribes have identified a different way to hunt, fish rather the using common tools such as fishnet, spear and so on. Fruits of Catunarega spinosa (Gela/ Mountain Pomegranate), and pods of Abrus precatorius (Gunj/ Rosary pea), act as a poison for the fish and cause - the state of unconsciousness. These fruits are initially dried, powdered and sprinkled in the water which acts as a poison/toxin for fish. Similarly, Aborigine tribes of the Xingu Area in Brazil, use Ichthyotoxin plants, which are crushed into pieces and added to bait or mixed in water, which narcotize the fish that they rise above the water surface (Gabriel et. al, 2008). 
Stomach aches, body aches, snake bites and fever are reported to be the common issues in the tribal areas, due to the tough topography and extensive physical work in the fields. In order to treat these disorders, tribal communities have developed ways to treat these disorders, through external application of some wild plants. Leaves of Moringa concanensis (Ran Shegut/ Konkan Moringa) and Cleome viscose (Supali/ Asian spider flower), are boiled and the water is used for bathing to treat body aches and fever. Other than these, the tribal communities have identified 2 climber species, both locally called as "Tanvel", to treat stomach ache in infants. The shoots of Stephania japonica (Snake vine) are tied to the ankle of male child as a bangle, while shoots of Cyclia peltata (Pata root) are tied to the ankle of a female child. Discussions with the tribes indicated the technique, to be very effective for children in curing stomach ache. The reason for this technique is not being used for adults, is not known to the tribes, as they claim it as a traditional practice. Similarly, roots of Ficus exasperate (Sandpaper tree) are tied to the horns of cattle, in case of cataract as an ethno veterinary remedy.

Another serious issue like Snake bites, which is a common phenomenon in the study area, is also tackled in similar ways by the tribes. Irrespective of several traditional remedies, which involve consumption or application of paste of plants in the area of bite, tribal community have developed a remedy in which the stem of Casearia graveolens (Chilla), is kept on the ear of the person as cure for snake bite. It is difficult to understand the scientific implication of this method, but the tribes have faith in this practice and have mentioned it to be useful, in such cases. There have been no reports of any deaths, after practicing this method, but the chances of snake bite being of non-venomous snakes are high.

Bauhinia racemosa (Kuharool/ Bidi Leaf Tree), is commonly found in the study area, and as the name suggests, is mostly used to make "Bidis" (Locally made cigarettes) by the tribal community, for smoking purposes. Even though it is a local wild plant, it impacts the health of the tribes causing respiratory problems. But, the tribal communities have identified a plant species, which help cure severe headaches after smoking. The stem of Trichodesma indicum (Indian Borage) is dried and smoked, during severe migraine. This plant is smoked, only during a migraine and not otherwise. Another plant Pogostemon benghalensis (Phangala/ Bengal Pogostemon), was reported to be of key significance and been peculiarly used by the local tribes. Fresh leaves of this plant are used as a bed bug repellent.

Thus, the tribal communities use several plant species in specific ways, for various day to day applications. Even though they are not aware about the reason for these practices, they have been following it for ages.

\section{CONCLUSIONS}

Lately, modernization has proved to be a strong driver towards the rapid decline in this traditional knowledge. Reasons for the same could be attributed to lack of interest expressed by the younger generations in getting involved in documenting traditional practices. Hence, more of such studies need to be undertaken in various tribal areas of India to document the perception of these wild plants. Even though the tribal communities are claiming the use of these wild edibles to be successful, validation of these practices needs to be undertaken through proper scientific studies which would help in understanding the authenticity of these practices.

\section{ACKNOWLEDGEMENTS}

At the outset, the authors thank JSW Steel Ltd for funding the study "Bio prospecting of the local wild edible varieties to address the issue of malnourishment in Palghar district" under which, these observations were recorded. Special thanks to Ms. Revati Gindi, for help during field work and identification of plants. At the end, the authors sincerely acknowledge all the help extended by the local tribal communities and also for sharing this information. 


\section{REFERENCES}

1. Almeida, M. R (2003).Flora of Maharashtra Vol. IV. Orient Press, Mumbai.

2. Bhogaonkar P., Marathe V., Khsirsagar P. (2010). Documentation of Wild Edible Plants of Melghat Forest, Dist. Amravati, Maharashtra State, India, Ethnobotanical Leaflets 14 (7) 51-58.

3. Chothe A., Patil S., Kulkarni D (2014). Unconventional wild fruits and processing in tribal area of Jawhar, Thane District, Bioscience Discovery, 5(1) 19-23.

4. D'souza (1999). The ethical principles followed by vaidus, Indian Journal of Medical Ethics, Vol 7 (1).

5. Deshmukh B. and Waghmode A. (2011). Role of wild edible fruits as a food resource: Traditional knowledge; International Journal of Pharmaceutical \& Life Sciences, 2 (7) 919-924.

6. Dhore, Lachure, Bharsakale, Dabhadkar (2012). Exploration of Some Wild Edible Plants of DigrasTahsil, Dist. - Yavatmal, Maharashtra, India, International Journal of Scientific and Research Publications, 2 (5).

7. Gabriel, O., Lange, K., Dahm, E. and Wendt, T. eds. (2008).Fish catching methods of the world, John Wiley \& Sons.

8. Garud B., Yadav S., Borale R. (2010). Traditional knowledge of plants of western Khandesh region of Maharashtra for snake bites; International Journal of Plant Sciences, 5 (1) 337-339.

9. Nene Y. L. (2004). Plant species utilized as food during famines and their relevance today, Asian AgriHistory, (8) 267-278.

10. Oak G., Kurve P., Kurve S., Pejavar M. (2015). Ethno-botanical studies of edible plants used by tribal women of Thane District, Journal of Medicinal Plants Studies; 3(2) 90-94.

11. Palekar (1993), Ethno - Medical Traditions of Thakur Tribals of Karjat, Maharashtra, Ancient Science of Life, Vol No. XIV (3 \& 4) $388-393$.

12. Patil P., Taware S., Kulkarni D. (2014). Traditional knowledge of broom preparation from Bhor and Mahad region of western Maharashtra, India, Bioscience Discovery, 5(2) 218-220.

13. Pranjale A., Dube K. (2015). Ethno-Veterinary Traditional Knowledge of Some Plants Used in Wardha district (Maharashtra), International Journal of Science and Research, 2319-7064.

14. Reddy (2012). Wild edible plants of Chandrapur district, Maharashtra, India; Indian Journal of Natural Products and Resources, Vol. 3(1) 110- 117.

15. Thamizoli P. and BaPisupati B. (2015). Sustainable Development-Stories from those making it Possible. Fledge, India.

16. WIPO (Undated). Retrieved fromhttp://www.wipo.int/tk/en/tk/.

17. Yesodharan K. and Sujana K. (2007). Wild edible plants traditionally used by the tribes in the Parambikulam Wildlife Sanctuary, Kerala, India, Natural Product Radiance, Vol 6(1). 